\title{
IRRADIAÇÃO E PASTEURIZAÇÃO DE PIMENTA DEDO-DE-MOÇA IN NATURA E EM POLPA
}

\author{
Regina Célia Rodrigues de Miranda Milagres ${ }^{1}$, Solange Guidolin Canniatti Brazaca ${ }^{2}$, Cleide Maria Ferreira
}

Pinto $^{3}$, Claudia Lúcia de Oliveira Pinto ${ }^{4}$

\begin{abstract}
RESUMO - Avaliar os efeitos da irradiação e da pasteurização sobre a vida útil de pimenta Dedo-de-moça Capsicum baccatum var. pendulum in natura e em polpa. Métodos: Realizaram-se três experimentos. Experimento 1: pimentas in natura tratadas com radiação gama do ${ }^{60} \mathrm{Co}$ (doses de 1,2 e $3 \mathrm{kGy}$ ), estocadas a $5^{\circ} \mathrm{C} / 30 \mathrm{dias}$, analisados quanto ao teor de carotenoides. Experimentos 2 e 3: pimentas processadas na forma de polpa e adicionadas de ácido cítrico $5 \%$. No experimento 2, as polpas foram expostas a 2 e $3 \mathrm{kGy}$, estocagem a $25^{\circ} \mathrm{C} /$ 60 dias e análises de mesófilos aeróbios, sólidos solúveis (SS), pH e cor. No experimento 3 avaliou-se a dose de $3 \mathrm{kGy}$, a pasteurização em bancada $\left(85^{\circ} \mathrm{C} / 3 \mathrm{~min}\right)$ em polpas conservadas a $25^{\circ} \mathrm{C}$. Realizou-se análises de $\mathrm{pH}, \mathrm{SS}$, cor, umidade, acidez titulável e ratio. Resultados: Houve aumento do teor de carotenoides $\left(\overline{\mathrm{x}} 86 \mu \mathrm{g} \cdot \mathrm{g}^{-1}\right)$ na pimenta in natura irradiada, entretanto ocorreu degradação mais rápida dos frutos (experimento 1). Polpas de pimenta irradiadas com 2 e 3 kGy não alteraram pH ( $(\bar{x} 4,8)$ e SS ( $\bar{x} 10,3)$, mas modificaram a cor. Constatouse inibição de mesófilos na dose de 3 kGy. Pasteurização e irradiação ( 3 kGy) permitiram aumento de 6 dias na vida útil da polpa (experimentos 2 e 3). Conclusão: Considerando que doses até 3 kGy não conservaram a pimenta in natura, mais estudos são necessários para estabelecer doses efetivas. $\mathrm{O}$ aumento em seis dias da vida útil da polpa submetida a irradiação ( $3 \mathrm{kGy}$ ) e a pasteurização indicou a viabilidade desses métodos para sua conservação.
\end{abstract}

Palavras-chave: conservação de alimentos, Capsicum, radiação.

\section{IRRADIATION AND PASTEURIZATION OF DEDO-DE-MOÇA PEPPER IN NATURA AND PULP}

\begin{abstract}
Objective: To assess the effects of irradiation and pasteurization on the shelf-life of pepper (Dedode-moça) Capsicum baccatum var. pendulum in natura and in pulp. Methods: Three experiments were conducted: experiment 1: in natura fruits were exposed to ${ }^{60} \mathrm{Co}$ gamma radiation (doses of 1, 2 and $3 \mathrm{kGy}$ ), stored at $5{ }^{\circ} \mathrm{C} / 30$ days and analyses for contents of carotenoids. Experiments 2 and 3: pepper processed in pulp and added of 5\% citric acid. In experiment 2, the doses 2 and $3 \mathrm{kGy}$ were evaluated in the pulp, stored at $25{ }^{\circ} \mathrm{C} / 60$ days, aerobic mesophilic, soluble solids (SS), pH and instrumental color. In experiment 3, we evaluated the $3 \mathrm{kGy}$ dose and pasteurization $\left(85^{\circ} \mathrm{C} / 3 \mathrm{~min}\right.$ ) in samples stored at $25^{\circ} \mathrm{C}$ and analyzed for $\mathrm{pH}$, SS, color, moisture, titulable acidity and ratio. Results: There was increase of the contents of carotenoids ( $\bar{x} 86 \mathrm{mg} \mathrm{g}^{-1}$ ) in in natura radiated pepper, but there was faster degradation of the fruits (experiment 1 ). Pulps radiated with 2 and $3 k$ Gy did not change $p H(\bar{x} 4.8)$ and SS ( $\bar{x} 10.3)$ but change the color. It is found inhibition of mesophilic in the dose of $3 \mathrm{kGy}$. Pasteurization and radiation (3 kGy) increase 6 days in the useful life of the pulp (experiment 2 and 3). Conclusions: Account that doses up to $3 \mathrm{kGy}$ did not preserved the in natura pepper, more studies are needed to establish effective doses. The increase in six days of useful life of the radiated ( $3 \mathrm{kGy}$ ) and pasteurized pulp indicated the feasibility of these methods for their preservation.
\end{abstract}

Keywords: food preservation, Capsicum, radiation.

\footnotetext{
${ }^{1}$ Universidade Federal de Viçosa. E-mail para correspondência reginamilagres@ufv.br.

${ }^{2}$ Departamento de Agroindústria, Alimentos e Nutrição/Escola Superior de Agricultura "Luiz de Queiroz"/ Universidade de São Paulo.

${ }^{3}$ Pesquisadora na Empresa de Pesquisa Agropecuária de Minas Gerais, Epamig Regional Sudeste.
} 


\section{INTRODUÇÃO}

A insegurança alimentar constitui uma grande preocupação no mundo. A Food and Agriculture Organization - FAO publicou o relatório intitulado "O estado de insegurança alimentar no mundo" que destacou a necessidade de crescimento econômico para redução da fome, além dos pontos centrais da insegurança alimentar como: preços, distribuição e disponibilidade dos alimentos. Problemas relacionados à conservação e qualidade dos alimentos foram também abordados (FAO, 2012).

Um grande desafio à ciência e à sociedade é melhorar a alimentação das pessoas em prol do bem-estar social, da qualidade de vida e da boa saúde. Dentre as diversas formas que a ciência pode contribuir estão os conhecimentos sobre as técnicas de conservação e seus impactos sobre os nutrientes. Diferentes tratamentos físicos e químicos são usados para conservação de alimentos, no entanto, alguns podem causar perdas nutricionais e ou sensoriais, a exemplo dos métodos que empregam o calor (Rico et al., 2010). Altas temperaturas podem desnaturar enzimas com consequentes alterações indesejáveis, e comprometimento do sabor, cor, textura e qualidade nutricional (Valderrama, 2001).

Além do emprego do calor, a refrigeração é uma alternativa para conservação dos produtos frescos ou processados. Entretanto, o fator econômico é limitante no uso deste método, uma vez que existe a necessidade de se manter a cadeia do frio. Como alternativa ao emprego do calor, da refrigeração ou de aditivos químicos, a técnica de irradiação tem se mostrado eficaz. A radiação gama do 60-Cobalto vem sendo empregada para aumentar a estabilidade dos alimentos no armazenamento por inativar microrganismos patogênicos, bactérias deteriorantes, fungos filamentosos, leveduras, parasitas, insetos, e por retardar a maturação e inibir o brotamento em bulbos e tubérculos (Andrews et al., 1998; Morehouse, 2002).

A irradiação é considerada um excelente processo de conservação para alimentos de origem vegetal (Shahbaz et al., 2014; Xie et al., 2015; Zeng et al., 2015). Entretanto, são necessários estudos sobre a sua aplicação para cada tipo de alimento e conhecimento do seu efeito sobre a qualidade (IAEA, 2006). Desta forma, há grande interesse pelo desenvolvimento de pesquisas nesta área. Ramamurth et al. (2004) observaram que a radiação gama com a dose $2 \mathrm{kGy}$ resultou em aumento da vida útil de Capsicum minimamente processado associado a redução da população bacteriana inicial em 2 a 3 ciclos logarítmicos e inativação de bactérias do grupo coliformes, Listeria e Yersinia sem alteração da qualidade nutricional. Maior efetividade da irradiação, na dose de 10 kGy, em relação ao vapor para conservação de pimentavermelha em pó foi constatada por Rico et al. (2010) com redução de 5 ciclos logarítmicos na contagem microbiana e efeitos mínimos sobre as propriedades físico-químicas e funcionais.

A pasteurização também é efetiva para a conservação de alimentos por inativar enzimas e microrganismos termo sensíveis, com ocorrência de alterações mínimas no valor nutritivo e nas características sensoriais dos produtos (Bastos et al., 2008; Pelais et al., 2008).

Embora a pimenta Capsicum tenha relevância econômica expressiva pelo seu uso na culinária mundial, farmacologia, odontologia, medicina e produção de armas de autodefesa (Pinto et al., 2013), existem poucos estudos sobre a avaliação da técnica de irradiação para sua conservação. A maioria das pesquisas foi desenvolvida com pimenta desidratada ou em pó (Ramamurth et al., 2004; Jalili et al., 2010; Rico et al., 2010). Existem relatos dos efeitos da irradiação em Capsicum minimamente processada (Ramamurth et al., (2004), mas não há ainda, pesquisas sobre a avaliação das técnicas de irradiação e de pasteurização para conservação de polpa de pimenta.

Com base no exposto, objetivou-se avaliar as técnicas de irradiação e de pasteurização sobre a vida útil de pimenta Dedo-de-moça Capsicum baccatum var. pendulum in natura e na forma de polpa.

\section{MATERIAL E MÉTODOS}

Foram realizados três experimentos sequenciais. O primeiro com pimenta Dedo-de-moça in natura, o segundo e o terceiro com polpa oriunda do processamento dos frutos adicionada de ácido cítrico.

Experimento 1 - Pimenta Dedo-de-moça "in natura" irradiada

O experimento foi realizado na Planta Piloto da Escola Superior de Agricultura Luis de Queiroz-ESALQ/ USP. Empregou-se delineamento inteiramente aleatorizado - DIA, com três repetições. 


\section{Amostra}

Utilizou-se $5 \mathrm{~kg}$ de pimentas Dedo-de-moça, selecionadas pela coloração, grau de maturação, ausência de lesões, tamanhos e danos mecânicos. Em seguida, $60 \mathrm{~g}$ dos frutos foram pesados e colocados em 60 bandejas de poliestireno expandido (isopor) com dimensões de: $15 \times 15 \times 4 \times 0,5 \mathrm{~cm}$, recoberta com filme de cloreto de polivinila $-\mathrm{PVC}$ comercial.

\section{Irradiação e armazenamento}

Os frutos embalados foram irradiados, em irradiador Multipropósito de ${ }^{60} \mathrm{Co}$, no Instituto de Pesquisas Energéticas e Nucleares - IPEN em São Paulo-SP, com radiação gama do ${ }^{60} \mathrm{Co}$, nas doses de: 1 ; 2 e $3 \mathrm{kGy}$ e taxa de dose de 3,21 $\mathrm{kGy} \mathrm{h}^{-1}$. Após a irradiação as amostras irradiadas e controles (não irradiadas), foram armazenadas a $5^{\circ} \mathrm{C}(\mathrm{L} 90 \%$ UR $)$ em câmara fria e analisadas nos tempos: $1,7,15$ e 30 dias.

\section{Quantificação de carotenoides totais}

A quantificação de carotenoides totais foi realizada conforme método descrito por Umiel \& Gabelman (1971), com modificações propostas por Moretti et al. (1998).

\section{- Preparo da amostra e extração dos pigmentos}

Os frutos foram homogeneizados em mixer por $3 \mathrm{~min}$. A uma alíquota de $8 \mathrm{~g}$ do homogenato adicionouse $40 \mathrm{~mL}$ de acetona e a mistura foi homogeneizada por um minuto. Procedeu-se a filtração a vácuo em kitassato protegido com papel alumínio, para evitar a foto-oxidação dos pigmentos. Em seguida, o extrato foi rinsado, por duas vezes, com $25 \mathrm{~mL}$ de acetona. Adicionou-se $45 \mathrm{~mL}$ de hexano ao filtrado.

\section{- Partição das fases}

A solução resultante foi transferida para um funil de separação e deixada em repouso tempo suficiente para separação nítida das fases. Em seguida, foram transferidos $100 \mathrm{~mL}$ de água destilada para o funil de separação para realização da etapa de lavagem do hexano. Após a separação das fases, descartouse a fase inferior e procedeu-se a lavagem com água destilada por mais duas vezes. Após a última lavagem, transferiu-se o extrato hexano-pigmento para um balão volumétrico de $100 \mathrm{~mL}$ e completou-se o volume com hexano.

\section{- Determinação espectrofotométrica e cálculo da concentração}

A absorvância do extrato foi determinada em espectrofotômetro de UV visível modelo Shimadzu $U V-1800$, no comprimento de onda de $460 \mathrm{~nm}$. A concentração de carotenoides totais $\left(\mu \mathrm{g} \mathrm{g}^{-1}\right)$ foi calculada pela equação:

$$
C T\left(\mu g g^{-1}\right)=\frac{A \times V \times 10^{4}}{A_{1 \mathrm{~cm}}^{1 \%} \times m}
$$

Em que:

A = absorbância dos pigmentos a $460 \mathrm{~nm}$;

$\mathbf{V}=$ volume final da amostra $(\mathrm{mL})$;

$\mathbf{A}^{1 \%}{ }_{1 \mathbf{c m}}=$ coeficiente de extinção (2200);

$\boldsymbol{m}=$ peso da amostra $(\mathrm{g})$

Uma vez que, doses acima de $2 \mathrm{kGy}$ podem causar alterações sensoriais nos frutos in natura (IAEA, 2006), nos experimentos seguintes, testou-se a radiação gama na "polpa" processada a partir do fruto da pimenta.

\section{Experimento 2 - Polpa de pimenta Dedo-de-moça} irradiada e acidificada

Utilizou-se DIA, em esquema fatorial $3 \times 2$ com 4 parcelas subdivididas e 3 repetições. Correspondendo a: 3 - tratamentos (controle; 2 kGy e 3 kGy); 2 - acidificação (amostras acidificadas e não acidificada) e 4 - tempos de estocagem (1, 15, 30 e 60 dias).

\section{Amostra e Processamento da polpa de pimenta}

Para seleção das amostras seguiu-se os mesmos critérios do Experimento 1. As pimentas foram divididas em três lotes, os quais foram processados separadamente na Planta Piloto da ESALQ/USP.

O processamento da pimenta, devidamente selecionada, foi realizado de acordo com as boas práticas de fabricação (BPF). Utilizaram-se frutos sem pedúnculo. $\mathrm{Na}$ Figura 1 são apresentadas as etapas do processamento da polpa de pimenta.

\section{Irradiação}

A irradiação foi realizada no Laboratório de Melhoramento de Plantas do Centro de Energia Nuclear na Agricultura (CENA/USP). Após envase, a polpa, foi tratada com radiação gama utilizando-se fonte de 


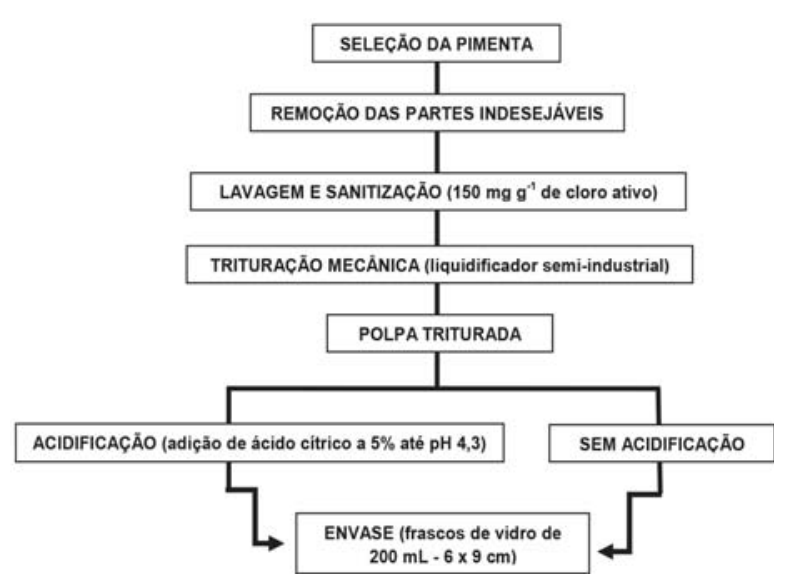

Figura 1 - Esquema do processamento da polpa de pimenta Dedo-de-moça acidificada e não acidificada.

${ }^{60} \mathrm{Co}$, em irradiador Gamma-Cell 220, a temperatura ambiente, nas doses de: 2 e $3 \mathrm{kGy}$ e taxa de dose de $0,368 \mathrm{kGy} \mathrm{h}^{-1}$. O tratamento controle consistiu de amostras não irradiadas.

\section{Armazenamento da polpa de pimenta}

Após o tratamento das amostras com radiação ionizante, procedeu-se o armazenamento a $25^{\circ} \mathrm{C}$, em estufa climatizada e, análises com 1, 15, 30 e 60 dias de estocagem.

\section{Análises}

Microbiológica: realizou-se a contagem de microrganismos mesófilos aeróbios em placas com Plate Count Agar (Ágar PCA-Merck ${ }^{\circledR}$ ) após a incubação a $37^{\circ} \mathrm{C}$, por 24 a 48 horas. Os resultados foram expressos em unidades formadoras de colônia por mililitro de polpa (UFC $\mathrm{mL}^{-1}$ ) de acordo com procedimento proposto pela American Public Health Association - APHA, descrito por Morton (2001).

Sólidos solúveis - (SS): utilizou-se refratômetro digital, conforme as normas da Association of Official Analytical Chemists (AOAC, 2005). Os resultados foram expressos em ${ }^{\circ}$ Brix.

$p H$ : foi determinado em potenciômetro e os resultados foram expressos em unidade de $\mathrm{pH}$ (AOAC, 2005).

Cor: foi determinada por reflectância em colorímetro Minolta, Modelo Chroma Meter CR-200b conforme proposto por Bible \& Singha (1993). As coordenadas de cor foram medidas em relação à placa branca. $\mathrm{O}$ valor $\mathrm{L}$ forneceu a luminosidade, com variação do preto $(\mathrm{L}=0)$ ao branco $(\mathrm{L}=100)$. O valor $a^{*}$ caracteriza a coloração na região do vermelho $\left(+a^{*}\right)$ ao verde ($\left.a^{*}\right)$ e o valor $b^{*}$ indica a coloração no intervalo do amarelo $\left(+b^{*}\right)$ ao azul $\left(-b^{*}\right)$.

Experimento 3 - Polpa de pimenta Dedo-de-moça acidificada submetida à irradiação ou à pasteurização

O estudo foi realizado em esquema fatorial $3 \times 2$ com 3 parcelas subdivididas, 3 repetições, em DIA. Correspondendo a: 3 tratamentos (irradiação; pasteurização e controle); 2 embalagens (frascos de vidro e embalagem aluminizada multicamadas) e 3 tempos de estocagem (1, 15 e 30 dias).

\section{Amostras e Processamento da polpa de pimenta}

A seleção e o processamento da polpa de pimenta foram realizados na Planta Piloto da ESALQ/USP, seguindo-se os procedimentos descritos nos experimentos 1 e 2 .

\section{Foram avaliados os tratamentos:}

\section{- Embalagens}

1. Embalagem aluminizada multicamadas sobrepostas: PET 15U - politereftalato de etila (poliéster); OPA 15U - poliamida biorientada (nylon); CPP 70U (ou PP Cast) - polipropileno obtido por extrusão e alumínio. Esta embalagem confere proteção à luz para os alimentos e resistência a $121^{\circ} \mathrm{C}$, por $45 \mathrm{~min}$.

2. Frascos de vidros transparentes com tampas rosqueáveis.

\section{- Pasteurização em bancada}

Após o envase, as polpas foram identificadas e pasteurizadas, individualmente, em bancada de acordo com método descrito por Bastos et al. (2008).

A contabilização do tempo de $3 \mathrm{~min}$ foi feita quando a amostra atingiu $85^{\circ} \mathrm{C}$, no centro geométrico (ponto frio). A temperatura foi aferida por imersão de termômetro com coluna de mercúrio em frasco de vidro e em embalagem multicamada aluminizada, as quais foram colocadas em banho-maria, junto às demais amostras. A pasteurização foi realizada separadamente considerandose que a condutividade térmica do vidro é menor que a da embalagem aluminizada. Após o tratamento térmico 
as amostras foram resfriadas até $40^{\circ} \mathrm{C}$ tomando-se cuidados para evitar o choque térmico na embalagem de vidro.

\section{-Irradiação}

Após processamento, as amostras foram tratadas com radiação gama em fonte de ${ }^{60} \mathrm{Co}$, a temperatura ambiente, no Laboratório de Melhoramento de Plantas do CENA/USP em Irradiador Gamma-Cell 220. Utilizouse a dose de radiação gama que obteve o melhor resultado no experimento 2 ( $3 \mathrm{kGy}$ ) e taxa de dose de $0,349 \mathrm{kGy} \mathrm{h}^{-1}$.

\section{Armazenamento}

Após os tratamentos de irradiação e pasteurização as amostras foram armazenadas a $25^{\circ} \mathrm{C}$, em estufa climatizada e analisadas em 3 tempos de estocagem (1, 15 e 30 dias $)$.

\section{Análises}

- $p H$, SS e Cor: conforme item 3.2.2.5 (AOAC, 2005; Bible \& Singha, 1993)

- Umidade: método gravimétrico, em estufa a $105{ }^{\circ} \mathrm{C}$, até peso constante (AOAC, 2005);

- Acidez Titulável (AT): determinada por titulação potenciométrica. Os resultados foram expressos em mg $100 \mathrm{mg}^{-1}$ de ácido cítrico (AOAC, 2005)

- Ratio: foi obtida pela relação direta dos valores de SS e AT.

\section{Análise estatística}

Os dados foram submetidos à análise da variância (ANOVA) e as médias dos tratamentos foram comparadas pelo teste de Tukey $(\mathrm{p}<0,05)$.

\section{RESULTADOS E DISCUSSÃO}

\section{Experimento 1 - Pimenta Dedo-de-moça “in natura” irradiada}

\section{Carotenoides totais}

A irradiação não afetou o teor de carotenoides totais (Figura 2) durante a estocagem. Houve maior perda de carotenoides (43\%) aos 30 dias de estocagem, na amostra controle. Maior média do teor do pigmento $(96,8 \mu \mathrm{g} \mathrm{g}$ $\left.{ }^{1}\right)$ foi observada em amostras irradiadas com a dose 1 kGy. Houve aumento de $9 \%$ do teor do pigmento aos
30 dias de estocagem para a dose de $2 \mathrm{kGy}$ e de $4 \%$ para amostras irradiadas com $3 \mathrm{kGy}$ aos 7 dias (Figura 2).

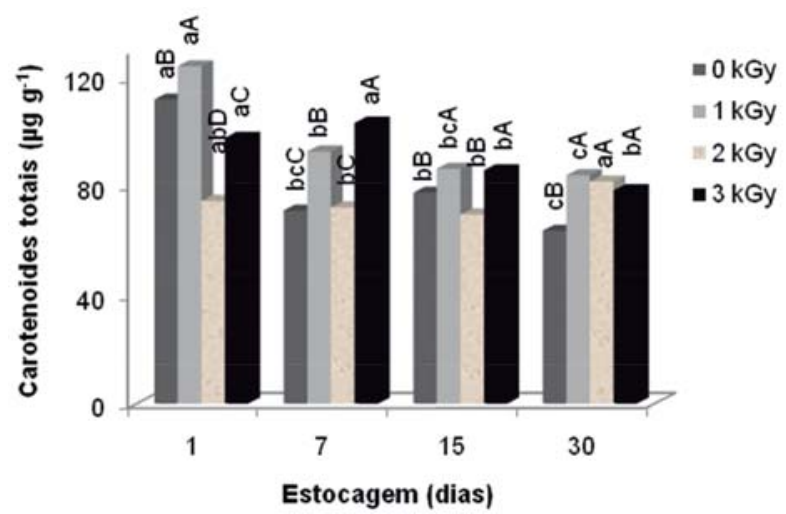

Figura 2 - Carotenoides totais em pimenta Dedo-de-moça irradiada e armazenada a $5^{\circ} \mathrm{C}$ por 30 dias. Médias seguidas pela mesma letra (maiúsculas em relação às doses e minúsculas aos dias de armazenamento) não diferem entre si (Tukey, $\mathrm{p}<0,05$ ).

Diferenças na conservação do pedúnculo entre os frutos irradiados e não irradiados foram observados após 15 dias de estocagem. Verificou-se nas pimentas irradiadas, degradação mais rápida comparada às amostras controle, além de maior perda de turgidez, deterioração do pedúnculo e crescimento microbiano.

Diante destas observações e uma vez que nas avaliações realizadas, aos 7, 15 e 30 dias de estocagem, as amostras irradiadas apresentaram os maiores teores de carotenoides totais, infere-se que a radiação gama acelerou a maturação da pimenta. Esta afirmativa se fundamenta na premissa de que na maturação dos frutos ocorre a degradação da clorofila, a síntese de carotenóides e a reação de oxidação (Lima et al., 2001). Em estudos realizados com manga e melão irradiados na dose de 2 kGy (Thomas \& Beyers, 1979) e com melão tratado com $0,45 \mathrm{kGy}$ (Siqueira, 2007) também foi observado aumento do teor de carotenoides totais.

Com base nos resultados do experimento 1, constatou-se que doses de radiação de até 3 kGy não são efetivas para ampliar a vida útil da pimenta Dedode-moça in natura, estocada a $5{ }^{\circ} \mathrm{C}$.

\section{Experimento 2-Polpa de pimenta Dedo-de-moça irradiada e acidificada}

A radiação gama, na dose de $3 \mathrm{kGy}$, em amostras acidificadas e não acidificadas, inibiu o crescimento 
de microrganismos mesófilos aeróbios até 60 dias de estocagem, a $25^{\circ} \mathrm{C}$. Nos demais tratamentos evidenciouse aumento dessa microbiota em até 4 ciclos logarítmicos (Tabela 1).

Os íons reativos produzidos durante a irradiação com raios gama danificam e destroem os microrganismos imediatamente, alteram a estrutura da membrana celular e afetam a atividade de enzimas metabólicas. Entretanto, o efeito mais importante da radiação nos microrganismos é sobre o DNA. Esses efeitos são aparentes após um determinado tempo no qual há comprometimento do mecanismo de duplicação do DNA e, em consequência, da divisão celular (Yokoya et al., 2008). Essa alteração no mecanismo de duplicação do DNA pode explicar os resultado encontrados no experimento 2 , em que a amostra irradiada com $3 \mathrm{kGy}$, após 1 dia da irradiação, apresentou crescimento de mesófilos e, nas demais avaliações realizadas ao longo da estocagem, esses organismos não foram detectados.

Ramamurthy et al. (2004) constataram redução de 2 a 3 ciclos logarítmicos na contagem de mesófilos em Capsicum minimamente processada irradiada com $2 \mathrm{kGy}$, após 1 dia da irradiação. A contaminação mantevese baixa durante 28 dias, em condições de refrigeração a $5{ }^{\circ} \mathrm{C}$ e a $10^{\circ} \mathrm{C}$. Doses de 1 e $2 \mathrm{kGy}$ aplicadas em polpa de manga foram efetivas para reduzir a da contagem de mesófilos. Na estocagem a $3{ }^{\circ} \mathrm{C}$, embora tenha ocorrido aumento da contagem, este foi menor nas amostras irradiadas em relação ao controle (Youssef et al., 2004).

$\mathrm{A}$ irradiação não provocou alteração no $\mathrm{pH}$ e na concentração de SS, como pode ser observado nas avaliações realizadas no tempo 1 (Tabela 2). No entanto, durante a estocagem, houve aumento do $\mathrm{pH}$ e redução do teor de SS até 30 dias. Apenas nos tratamentos com doses de 2 e 3 kGy, sem adição de ácido, não houve alteração dos SS durante os 30 dias de estocagem (Tabela 2).

O teor de SS representa a concentração de açucares presentes nos frutos, embora outros compostos como ácidos, vitaminas, aminoácidos e algumas pectinas também façam parte deste índice em menor proporção (Kluge et al., 2002). Aos 60 dias houve, na maioria dos

Tabela 1 - Contagem de microrganismos mesófilos aeróbios (UFC mL $\mathrm{mL}^{-1}$ ) em polpa de pimenta Dedo-de-moça acidificada e não acidificada, irradiada e não irradiada, estocada a $25^{\circ} \mathrm{C}$

\begin{tabular}{lcccccc}
\hline \multirow{2}{*}{$\begin{array}{c}\text { Tempo } \\
\text { (dias) }\end{array}$} & \multicolumn{5}{c}{ Tratamentos } \\
\cline { 2 - 7 } & Controle & $2 \mathrm{kGy}$ & $3 \mathrm{kGy}$ & Controle ácido & $2 \mathrm{kGy}$ ácido & $3 \mathrm{kGy}$ ácido \\
\hline 1 & $3,3 \times 10^{\circ} \mathrm{bA}$ & $<1 \mathrm{bA}$ & $8,0 \times 10^{1} \mathrm{aA}$ & $<1 \mathrm{bA}$ & $3,3 \times 10^{\circ} \mathrm{bA}$ & $<1 \mathrm{bA}$ \\
15 & $<1 * \mathrm{bA}$ & $<1 \mathrm{bA}$ & $<1 \mathrm{bA}$ & $<1 \mathrm{bA}$ & $3,3 \times 10^{\circ} \mathrm{bA}$ & $<1 \mathrm{bA}$ \\
30 & $2,7 \times 10^{\circ} \mathrm{bA}$ & $1,0 \times 10^{1} \mathrm{bA}$ & $<1 \mathrm{bA}$ & $<1 \mathrm{bA}$ & $1,0 \times 10^{\circ} \mathrm{bA}$ & $<1 \mathrm{bA}$ \\
60 & $2,1 \times 10^{3} \mathrm{aBC}$ & $1,6 \times 10^{4} \mathrm{aA}$ & $<1 \mathrm{bA}$ & $3 \times 10^{1} \mathrm{aC}$ & $1,2 \times 10^{4} \mathrm{aAB}$ & $<1 \mathrm{aC}$ \\
\hline
\end{tabular}

* Valor estimado; Médias seguidas pela mesma letra (maiúsculas na linha e minúsculas na coluna) não diferem entre si ( $<<0,05)$.

Tabela 2 - pH e SS em polpa de pimenta Dedo-de-moça irradiada e não irradiada estocada a $25^{\circ} \mathrm{C}$

\begin{tabular}{lcccccc}
\hline \multirow{2}{*}{$\begin{array}{c}\text { Tempo } \\
\text { (dias) }\end{array}$} & Controle & $2 \mathrm{kGy}$ & $3 \mathrm{kGy}$ & Controle ácido & $2 \mathrm{kGy}$ ácido & $3 \mathrm{kGy}$ ácido \\
\cline { 2 - 7 } & & \multicolumn{5}{c}{$\mathrm{pH}$} \\
1 & $4,9 \pm 0,04 \mathrm{bA}$ & $5,0 \pm 0,02 \mathrm{cA}$ & $5,0 \pm 0,02 \mathrm{cA}$ & $4,4 \pm 0,30 \mathrm{bB}$ & $4,4 \pm 0,02 \mathrm{bB}$ & $4,4 \pm 0,06 \mathrm{bB}$ \\
15 & $5,0 \pm 0,07 \mathrm{abB}$ & $5,3 \pm 0,02 \mathrm{aA}$ & $5,3 \pm 0,00 \mathrm{bA}$ & $4,6 \pm 0,03 \mathrm{aC}$ & $4,7 \pm 0,01 \mathrm{aC}$ & $4,7 \pm 0,00 \mathrm{aC}$ \\
30 & $5,1 \pm 0,04 \mathrm{aB}$ & $5,2 \pm 0,02 \mathrm{abB}$ & $5,6 \pm 0,46 \mathrm{aA}$ & $4,5 \pm 0,05 \mathrm{abD}$ & $4,7 \pm 0,01 \mathrm{CD}$ & $4,9 \pm 0,03 \mathrm{aC}$ \\
60 & $5,0 \pm 0,02 \mathrm{abA}$ & $5,0 \pm 0,01 \mathrm{bcA}$ & $5,0 \pm 0,00 \mathrm{cA}$ & $4,3 \pm 0,04 \mathrm{bB}$ & $4,4 \pm 0,01 \mathrm{bB}$ & $4,4 \pm 0,01 \mathrm{bB}$ \\
& & & $\mathrm{SS}\left({ }^{\circ} \mathrm{Brix}\right)$ & & \\
1 & $10,0 \pm 0,15 \mathrm{bB}$ & $10,2 \pm 0,06 \mathrm{bAB}$ & $10,4 \pm 0,06 \mathrm{bAB}$ & $10,9 \pm 0,30 \mathrm{aA}$ & $10,6 \pm 0,06 \mathrm{bAB}$ & $10,2 \pm 0,29 \mathrm{bAB}$ \\
15 & $9,4 \pm 0,06 \mathrm{bA}$ & $10,1 \pm 0,17 \mathrm{bA}$ & $9,9 \pm 0,06 \mathrm{bA}$ & $9,9 \pm 0,15 \mathrm{bAB}$ & $10,1 \pm 0,17 \mathrm{bcA}$ & $9,9 \pm 0,06 \mathrm{bcA}$ \\
30 & $7,3 \pm 0,06 \mathrm{cB}$ & $10,1 \pm 0,21 \mathrm{bA}$ & $9,9 \pm 0,06 \mathrm{bA}$ & $9,7 \pm 0,21 \mathrm{bA}$ & $9,6 \pm 0,36 \mathrm{cA}$ & $9,5 \pm 0,36 \mathrm{cA}$ \\
60 & $11,5 \pm 0,9 \mathrm{aBC}$ & $11,8 \pm 0,36 \mathrm{aABC}$ & $11,4 \pm 0,15 \mathrm{aC}$ & $11,4 \pm 0,64 \mathrm{aBC}$ & $12,4 \pm 0,23 \mathrm{aA}$ & $12,1 \pm 0,42 \mathrm{aAB}$ \\
\hline
\end{tabular}

*Médias seguidas pela mesma letra (maiúsculas na linha e minúsculas na coluna) não diferem entre si ( $\mathrm{p}<0,05)$. 
tratamentos, inversão da tendência apresentada até os 30 dias, ou seja, redução do pH e aumento de SS (Tabela 2). O aumento no teor de SS pode ser atribuído à perda de umidade durante o armazenamento em temperatura de $25^{\circ} \mathrm{C}$ (Lima et al., 2001). A redução do pH após 30 dias pode ser associada à contaminação da polpa com bactérias produtoras de ácidos, o que corrobora com os resultados das análises microbiológicas, em que a contaminação com mesófilos constatada no tempo 60 foi significativamente maior. No entanto, o crescimento de mesófilos foi inibido com $3 \mathrm{kGy}$, mas ainda assim houve redução do pH após 30 dias. É possível ter havido crescimento de microrganismos anaeróbios, que não foram detectados na análise para mesófilos aeróbios. De acordo com Bach (2012) microrganismos anaeróbios são, em geral, fermentadores de hidratos de carbono e, desta forma, pode ocorrer fermentação e, em consequência, liberação de compostos ácidos, associados à redução do $\mathrm{pH}$.

Os efeitos da irradiação sobre o pH e o teor de SS podem variar de acordo com a espécie vegetal. Por exemplo, o teor de SS em romãs não foi afetado com a aplicação das doses de radiação de 0,4; 1 e 2 kGy, mas houve aumento do $\mathrm{pH}$ nas amostras irradiadas com 2 kGy (Shahbaz et al., 2006). Em contraste, Moreno et al. (2007) verificaram que em frutos de mirtilo irradiados com até 3,2 kGy não houve alteração do pH.

\section{Cor}

Por meio da avaliação colorimétrica observou-se diferenças entre os tratamentos $(p<0,05)$, com exceção das amostras acidificadas e irradiadas com doses de 2 e 3 kGy que permaneceram estáveis. Os valores de luminosidade (L) variaram entre 35 e 43,7. Este índice apresentou decréscimo até o trigésimo dia de estocagem, resultado indicativo de ocorrência de escurecimento das amostras, provavelmente, pela degradação do pigmento carotenoide da pimenta. De acordo com Youssef et al., (2002), alterações de cor podem ser atribuídas a alta atividade da polifenoloxidase. Esta enzima, em contato com o oxigênio, provoca a oxidação dos compostos fenólicos com liberação de água e de quinona que é um composto colorido. Estes autores também evidenciaram variação da cor, em polpa de manga irradiada, com doses até $2 \mathrm{kGy}$

Não houve alteração significativa no parâmetro $a^{*}$, que variou de 15,5 a 21 , durante a estocagem, exceto para a dose de $2 \mathrm{kGy}$ em que ocorreu aumento da intensidade da cor vermelha. No parâmetro $b^{*}$ os valores variaram entre 17 e 35 , ao longo da estocagem, em todos os tratamentos, com tendência para a cor amarela, o que indica perda da cor natural da polpa. O único tratamento que não alterou foi aquele em que aplicouse a dose de 2 kGy e acidificação.

\section{Experimento 3 - Polpa de pimenta Dedo-de-moça acidificada submetida à irradiação ou à pasteurização}

Todas as amostras controle apresentaram estufamento, vazamento de líquido na embalagem e visível produção de gás após 3 dias de estocagem, a $25^{\circ} \mathrm{C}$. Em amostras irradiadas e ou pasteurizadas este resultado também foi observado após 9 dias.

Na Figura 3 são apresentados os resultados das análises físico-químicas da polpa, após 1 dia de estocagem, uma vez que não foram realizadas as avaliações de 15 e 30 dias em função da contaminação das amostras. Não houve diferença $(\mathrm{p}<0,05)$ nos resultados das avaliações físico-químicas entre os tratamentos.

As coordenadas $L, a^{*}$ e $b^{*}$ não foram influenciadas pela irradiação $(\mathrm{p}<0,05)$. A pasteurização alterou os valores de $a^{*}$ e $b^{*}$ da polpa. Nas amostras pasteurizadas e armazenadas em frascos de vidro houve aumento dos valores de $a^{*}(15 \pm 1,5$ para $20 \pm 2,4)$ e $b^{*}(20$ $\pm 2,4$ para $30 \pm 4,0$ ) em relação ao controle, ou seja, tornaram-se mais alaranjada.

Os resultados encontrados revelaram que a dose de radiação gama de 3 kGy e o binômio tempo/temperatura usado na pasteurização controlaram a deterioração das amostras, por seis dias a mais do que o controle. No entanto, esta mesma dose no experimento 2 controlou a deterioração da polpa por 30 dias, provavelmente porque a concentração de células microbianas residual presente na polpa após processamento, pode ter sido muito inferior a evidenciada na polpa do experimento 3 .

Este fato pode ter ocorrido em função de um alto grau de contaminação inicial na polpa, uma vez que, em produtos recém-colhidos há considerável variação na contagem de microrganismos mesófilos aeróbios, podendo chegar a 9 logs. Tal contaminação poderia ter sido controlada pelo aumento da dose de radiação. Iqbal et al. (2013) observaram em pimenta vermelha que a contaminação inicial, entre $10^{4}$ e $10^{7}$ ciclos logarítmicos, foi reduzida em 1 log na dose de $2 \mathrm{kGy}$. Na dose de 4 kGy houve redução de 2 a 3 logs e na 


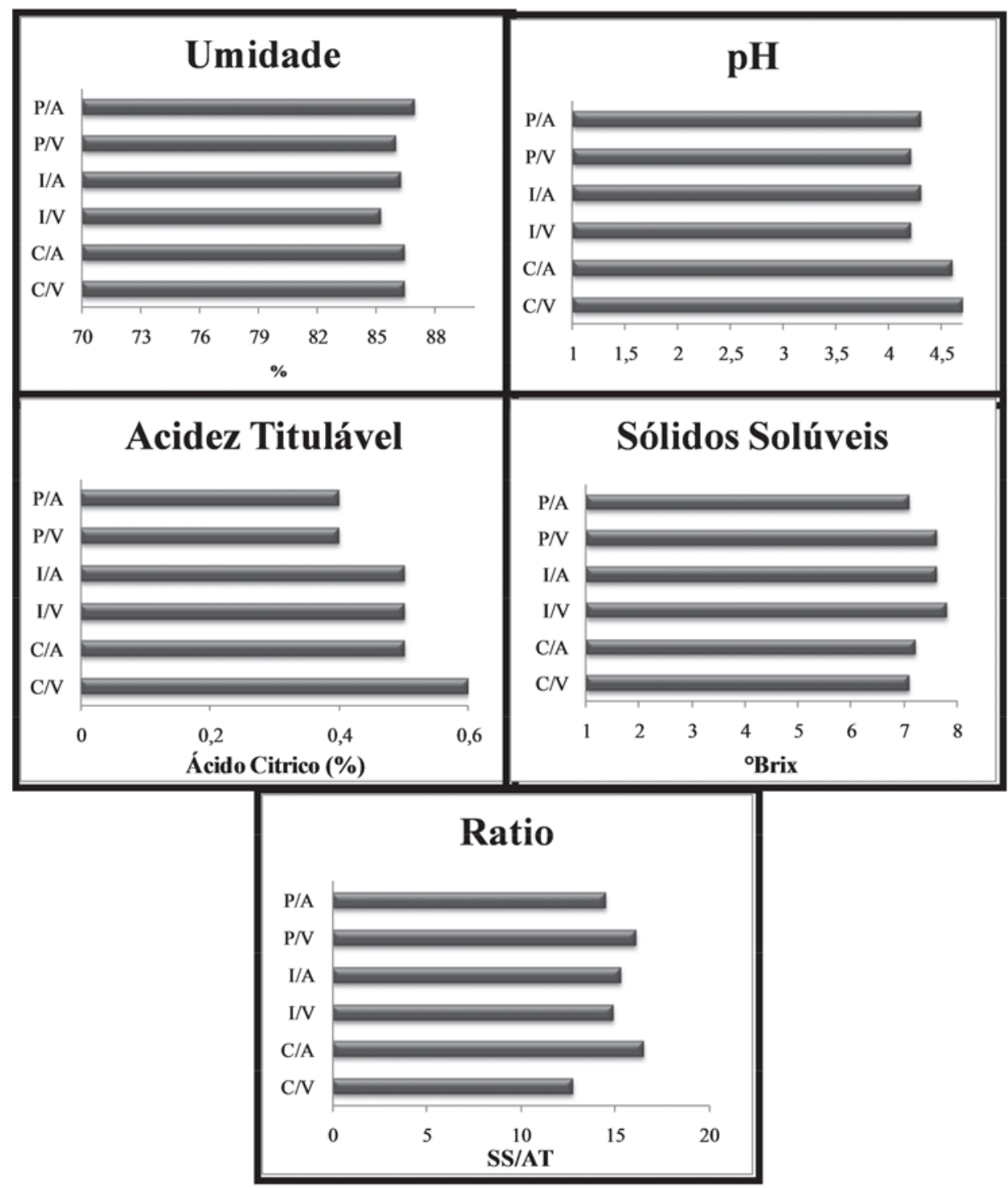

Figura 3 - Caracterização físico-química da polpa de pimenta Dedo-de-moça após 1 dia da irradiação e da pasteurização. $\mathrm{P} / \mathrm{A}=$ pasteurizada/embalagem aluminizada $; \mathrm{P} / \mathrm{V}=$ pasteurizada/ embalagem de vidro $; \mathrm{I} / \mathrm{A}=$ irradiada/embalagem aluminizada $; \mathrm{I} / \mathrm{V}=$ irradiada/ embalagem de vidro; $\mathrm{C} / \mathrm{A}=$ controle/ embalagem aluminizada $; \mathrm{C} / \mathrm{V}=$ controle/embalagem de vidro.

dose de 6 kGy a redução variou de 4 a 7 logs. No entanto, em produtos de origem vegetal, doses elevadas podem acelerar o metabolismo da planta.

Além da contaminação microbiana inicial, os procedimentos de lavagem e sanitização também podem influenciar a qualidade microbiológica do produto final. As etapas de seleção, lavagem e sanitização podem interferir de forma diferenciada nas populações e tipos de microrganismos presentes na matéria-prima. A utilização de água de boa qualidade para lavagem permite reduzir cerca de $1 \log$ da contaminação microbiona inicial. A sanitização tem eficiência limitada. O uso de sanitizantes apropriados para alimentos frescos permite reduzir de 1 a 2 ciclos logarítmicos, no entanto, pode favorecer o crescimento de microrganismos patogênicos pela redução da microbiota competitiva (Zagory, 1999). Em produtos minimamente processados, por exemplo, a 
contagem de bactérias mesófilas após processamento

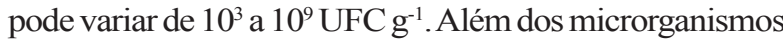
mesófilos, outros microrganismos como leveduras, coliformes e bactérias lácticas heterofermentativas produzem dióxido de carbono e gás.

Não houve diferença nos resultados das avaliações físico-químicas entre os tratamentos. Em outros estudos também foi demonstrado que a radiação gama do ${ }^{60} \mathrm{Co}$ não alterou as características físico-químicas de umidade, pH, AT, SS e ratio (Lima et al., 2001; Santos et al., 2010; Souza et al., 2012). Do mesmo modo, as coordenadas $L, a^{*} \mathrm{e} b^{*}$ não foram influenciadas pela irradiação.

A pasteurização não afetou as características físicoquímicas da polpa de pimenta, no entanto, Pelais et al. (2008) registraram que em polpa de muruci (Byrsonima crassifolia) as coordenadas $L, a^{*}$ e $b^{*}$ foram influenciadas pela temperatura da pasteurização em escala de bancada $(p<0,05)$. Bastos et al. (2008) também demonstraram variação significativa de cor $(p<0,05)$ em polpa de taperebá (Spondias mombim) pasteurizada.

\section{CONCLUSÃO}

Considerando que doses de radiação até 3 kGy não foram efetivas para aumentar a vida útil da pimenta Dedo-de-moça in natura, outros estudos são necessários para o estabelecimento de doses que sejam efetivas.

O aumento em seis dias da vida útil da polpa de pimenta, empregando-se a dose de radiação de $3 \mathrm{kGy}$ e a pasteurização, indicou a viabilidade desses métodos para conservação de pimenta processada na forma de polpa.

\section{LITERATURA CITADA}

ANDREWS, L.S.; AHMEDNA M.; GRODNER, R.M. et al. Food preservation using ionizing radiation. Reviews of Environmental Contamination and Toxicology, v.153, p. $1-53,1998$.

\section{ASSOCIATION OF OFFICIAL ANALYTICAL CHEMISTS. Official methods of analysis. 18. ed. Arlington, AOAC, 2005.}

$\mathrm{BACH}$, F. Avaliação das condições de produção de fermentado acético de soro de leite. Dissertação (Mestrado em Engenharia Química). Toledo, PR: UNIOEST; 2012, 136p.
BASTOS, C.T.D.R.M.; LADEIRA, T.M.H. et al. Estudo da eficiência da pasteurização da polpa de taperebá (Spondias mombin). Alimentos e Nutrição, v.19, n.2, p.123-131, 2008.

BIBLE, B. B.; SINGHA, S. Canopy position influences CIELAB coordinates of peach color. Hortscience, v. 28, n.10, p.992-993, 1993.

FOOD AND AGRICULTURE ORGANIZATION. The state of food insecurity in the world: economic growth is necessary but not sufficient to accelerate reduction of hunger and malnutrition. Roma, 2012. In: http://www.ft.dk/ samling/20121/almdel/uru/bilag/19/1168376/ index.htm. (acessado em 21 de julho de 2014).

INTERNATIONALATOMIC ENERGY AGENCY. Use of irradiation to ensure hygienic quality of fresh, pre-cut fruits and vegetables and other minimally processed food of plant origin. Vienna: FAO/IAEA, 2006.

IQBAL, S.; BHATTI, I.A.; ASI, M.R. et al. Effect of $g$ irradiation on fungal load and aflatoxins reduction in red chillies. Radiation Physics and Chemistry, v.82, p.80-84, 2013.

JALILI, M.; JINAP, S.; NORANIZAN, A. Effect of gamma radiation on reduction of mycotoxins in black pepper. Food Control, Guildford, v.21, n.10, p.1388-1393, 2010.

KLUGE, R. A; NACHTIGAL, J.C.; BILHALVA, A.B. Fisiologia e manejo pós-colheita de frutas de clima temperado. 2 ed. Campinas: Livraria e Editora Rural. 2002.

LIMA, K. S. C.; JORGE, L.S.; GROSSI, J.L.G. et al. Efeito da irradiação ionizante ã na qualidade póscolheita de cenouras (Doucos carota L.). Ciência e Tecnologia de Alimentos, v.21, p.202-208, 2001.

MOREHOUSE, M. Food irradiation: US regulatory considerations. Radiation Physics and Chemistry, v.63, p.281-284, 2002.

MORENO, M. A.; CASTELL-PEREZ, M.E.; GOMES, C. et al. Quality of electron beam irradiation of blueberries (Vacciniumcorymbosum L.) at medium dose levels (1.0-3.2 kGy). LWT Food Science and Technology, v.40, p.1123-1132, 2007. 
MORETTI, C. L.; SARGENT, S.A.; HUBER, D.J. et al. Chemical composition and physical properties of pericarp, locule and placental tissues of tomatoes with internal bruising. Journal of the American Society for

Horticultural Science, v.123, n.4, p.656-660, 1998.

MORTON, R. D. Microbiological Monitoring of the Food Processing Environment.

Compendium of methods for the microbiological examination of foods. 4 rd. [S.1.]. Washington DC: APHA, 2001. p.63-67.

PELAIS, A. C. A.; ROGEZ, H., PENA, R. S. Estudo da pasteurização da polpa de Murici. Revista Alimentos e Nutrição, v.19, n.1, p.17-24, 2008.

PINTO, C. M. F.; PINTO, C. L. O.; DONZELES, S. M. L. Pimenta capsicum: propriedades químicas, nutricionais, farmacológicas e medicinais e seu potencial para o agronegócio. Revista Brasileira de Agropecuária Sustentável, v.3, n.2, p.108-120, 2013.

RAMAMURTHY, M. S.; KAMAT, A.; KAKATKAR, A. et al. Improvement of shelf-life and microbiological quality of minimally processed refrigerated capsicum by gamma irradiation. International Journal of Food Sciences and Nutrition, Oxford, v.55, n.4, p.291-299, 2004.

RICO, C.W.; KIM, G.; AHN, J. et al. The comparative effect of steaming and irradiation on the physicochemical and microbiological properties of dried red pepper (Capsicum annum L.). Food Chemistry, v.119, p.1012-1016, 2010.

SANTOS, A. M. G.; OLIVEIRA, S.M.A.; SILVA, J.M. et al. Podridão por Fusicoccum em mangas submetidas a baixas doses de radiação gama.

Pesquisa Agropecuária Brasileira, Brasília, v.45, p.1066-1072, 2010.

SHAHBAZ, M. S.; AHN, J.; AKRAM, K. et al. Chemical and sensory quality of fresh pomegranate fruits exposed to gamma radiation as quarantine treatment. Food Chemistry, Barking, n.145, p.312-318, 2014.
SIQUEIRA, A. A. Z. C. Utilização de radiação gama em melões cantaloupe (Cucumis melo L. var. Cantaloupensis) como técnica de conservação pós colheita. Tese (Doutorado em Ciências). Piracicaba, SP: CENA-USP, 2007. 108p.

SOUZA, A.R.M; ARTHUR V.; NOGUEIRA, D.P. The effect of irradiation in the preservation of pink pepper (Schinus terebinthifolius Raddi). Radiation Physics and Chemistry, v.81, n. 8, p.1082-1083, 2012.

THOMAS, A. C.; BEYERS. M. ã Irradiation of Subtropical Fruits. 3. A comparison of the chemical changes occurring during normal ripening of mangoes and papayas with changes produced by y irradiation. Journal of Agricultural and Food Chemistry, v.27, n.1, 1979.

UMIEL, N.; GABELMAN, W. H. Analytical procedures for detecting carotenoids of carrot (Daucus carota L.) roots and tomato (Lycopersicon esculentum Mill) fruits. Journal of the American Society for Horticultural Science, v.96, n.6, p.702-704, 1971.

VALDERRAMA, P.; MARANGONI, F.;

CLEMENTE, E. Efeito do tratamento térmico sobre a atividade de peroxidase (POD) e polifenoloxidase (PPO) em maçã (Mallus comunis). Ciência e Tecnologia de Alimentos, v.21, n.3, p.321-325, 2001.

XIE, Z.; CHARLES, M.T.; FAN, J. et al. Effects of preharvest ultraviolet-C irradiation on fruit phytochemical profiles and antioxidant capacity in three strawberry (Fragaria ananassa Duch.) cultivars. Journal of the Science of Food and Agriculture, v.95, n.14, p.2996-3002, 2015.

YOKOYA, A.; SHIKAZONO, N.; FUJII, K et al. DNA Damage induced by the direct effect of radiation. Radiation Physics and Chemistry, v.77, n.10-12, p.1280-1285, 2008.

YOUSSEF, B. M.; ASKER, A.A.; EL-SAMAHY, S.K. et al. Combined effect of steaming and gamma irradiation on the quality of mango pulp stored at refrigerated temperature. Food Research International, v.35, p.1-13, 2002. 
ZAGORY, D. Effects of post-processing handling and packaging on microbial populations.

Postharvest Biology and Technology, v.15, n.3, p.313-321, 1999.
ZENG, F.; LUO, Z.; XIE, J. et al. Gamma radiation control quality and lignification of bamboo shoots (Phyllostachys praecox f. prevernalis) stored at low temperature. Postharvest Biology and Technology, v.102, p.17-24, 2015.

Recebido para publicação em 16/06/2016 e aprovado em 21/09/2016. 